\title{
International Space Exploration Coordination Group Assessment of Technology Gaps for LOx/Methane Propulsion Systems for the Global Exploration Roadmap
}

\author{
Eric A. Hurlbert, Ryan Whitley, Mark D. Klem, Wesley Johnson, and Leslie Alexander \\ National Aeronautics and Space Administration (NASA), USA \\ Emanuela D'Aversa \\ Agenzia Spaziale Italiana (ASI), Rome, Italy \\ Jean-Marc Ruault \\ Centre national d'études spatiales (CNES), Paris, France \\ Chiara Manfletti and Martin Sippel, \\ German Aerospace Center (DLR), Cologne, Germany \\ Jean-Noel Caruana \\ European Space Agency ESA, Paris, France \\ Hiroshi Ueno and Hiroya As akawa \\ Japan Aerospace eXploration Agency (JAXA), Tokyo, Japan
}

\begin{abstract}
As part of the Global Exploration Roadmap (GER), the International Space Exploration Coordination Group (ISECG) formed two technology gap ass essment teams to evaluate topic discipline areas that had not been worked at an international level to date. The participating agencies were ASI, CNES, DLR, ESA, JAXA, and NASA. Accordingly, the ISECG Technology Working Group (TWG) recommended two discipline areas based on Critical Technology Needs reflected within the GER Technology Development Map (GTDM): Dust Mitigation and LOX/Methane Propulsion. LOx/Methane propulsion sys tems are enabling for future human missions Mars by significantly reducing the landed mass of the Mars ascent stage through the use of in-situ propellant production, for improving common fluids for life support, power and propulsion thus allowing for diverse redundancy, for eliminating the corrosive and toxic propellants thereby improving surface operations and reusability, and for increasing the performance of propulsion systems. The goals and objectives of the international team are to determine the gaps in technology that must be closed for LOx/Methane to be us edin human exploration missions in cis-lunar, lunar, andMars mission applications. An emphasis is placedon near term lunar lander applications with extensibility to Mars. Fach agency provided a status of the substantial amount of Lox/Methane propulsion sys tem development to date and their inputs on the gaps in the technology that are remaining. The gaps, which are now opportunities for collaboration, are then discussed.
\end{abstract}




\section{Introduction}

$\mathrm{T}$

he International Space Exploration Coordination Group (ISECG) formed technology gap assessment teams to

evaluate topic discipline areas that had not been worked at an international level to date. The participating agencies were ASI, CNES, DLR, ESA, JAXA, and NASA. Accordingly, the ISECG Technology Working Group (TWG) selected two discipline areas based on Global Exploration Roadmap (GER) Critical Technology Needs reflected within the GER Technology Development Map (GTDM): Dust Mitig ation and LOX/Methane Propulsion. The goals and objectives of the international team are to determine the gaps in technology that must be closed for LOx/Methane sys tems to be used in human exploration missions in cis-lunar, lunar, and Mars mis sion applications. An emphasis is placed on near term lunar lander applications with extensibility to Mars.

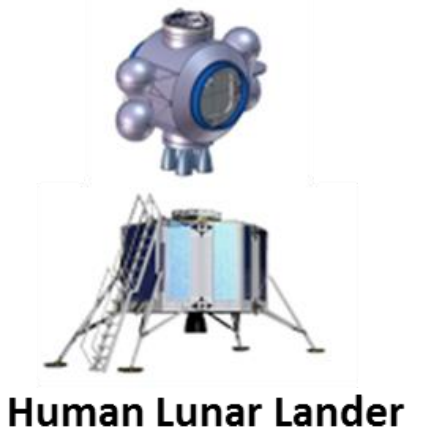

Human Lunar Lander

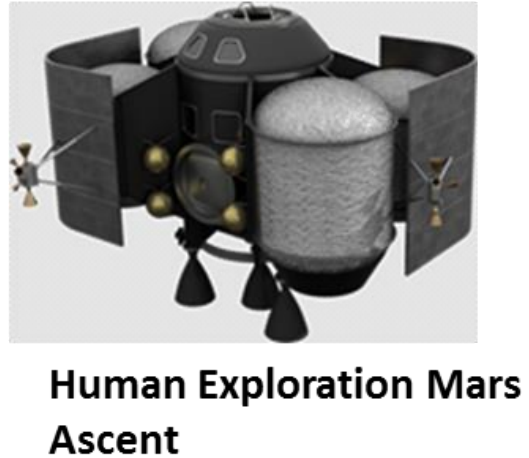

Ascent

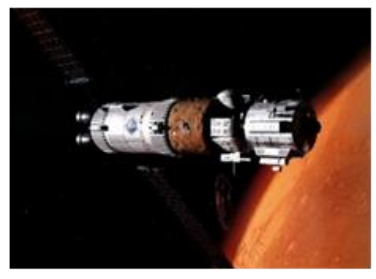

Orbital (In Space) Transfer Vehicle

\section{Mission and Vehicles Evaluated for LOx/Methane Technology Gaps}

LOx/Methane has application to in-space propulsion systems, such as service modules, landing or descent vehicles, and as cent stages. LOx / Methane propulsion can also be considered for access to space due to its low cost, high thrust and applicability to reus able engines for $1^{\text {st }}$ stages of launchers, as well as to re-ignitable engines for upper stages. This wide range of applicability should allow for some economy in the development of the required technologies. The fact that LOx is being used also allows for leveraging of existing technologies in many cases.

\section{A. Lunar Lander concept}

ISECG IAWG(International Architecture Working Group) developed the lunar surface mis sion scenario shown in Figure 1. The human lunar lander is a component of a dual launch mission concept. The lander arrives and rendezvouses with the evolvable Deep Space Habitat (eDSH) and loiters until the crew arrives on a separate launch. After docking, the crew transfers via the eDSH to the lander. The lander carries crew and cargo to the lunar surface and returns crew and samples to the eDSH at the conclusion of surface ops.

There are two configurations under investigation for the lunar lander. Both configurations assume that the eDSH location is the NRO (Near Rectilinear Orbit) and transports four crew members to the surface. The main difference between configurations 1 and 2 is the descent stage.

Configuration 1 features a two-stage lander comprised of a descent module (DM) and ascent module (AM). The DM completes all descent maneuvers from the eDSH until touchdown. The DM is left on the surface of the moon while the AM returns to the eDSH for reuse. The cargo variant of the lander does not carry an AM.

Configuration 2 features a lunar module with crushable landing gear (the primary module or PM) combined with a drop stage (DS). The DS completes all descent maneuvers from the eDSH until it is safely disposed prior to 
touchdown. The crushable structural component of the PM is left on the surface of the moon while the rest of the PM returns to the eDSH for reuse. The cargo variant of the lander includes only the cru shable landing assembly and a DS. The descent module of configuration 1 is $2.7 \mathrm{~m}$ in height and $5.2 \mathrm{~m}$ in diameter. The main engine propellants are LOX/CH4. The main engines consist of three $30-\mathrm{kN}$ engines, and the RCS thrusters consist of forty $220-\mathrm{N}$ engines. The propellant tanks consist of three fuel, three oxidizer and four heliumtanks. The drop stage of the configuration 2 is described as the same as the descent module of configuration 1.

Both human lunar lander concepts meet the anticipated SLS 40-mT Trans-Lunar Insertion (TLI) capability (not considering the NRO insertion delta-V.). An early presence of the ascent stage in NRO could provide different benefits to the overall exploration campaign.

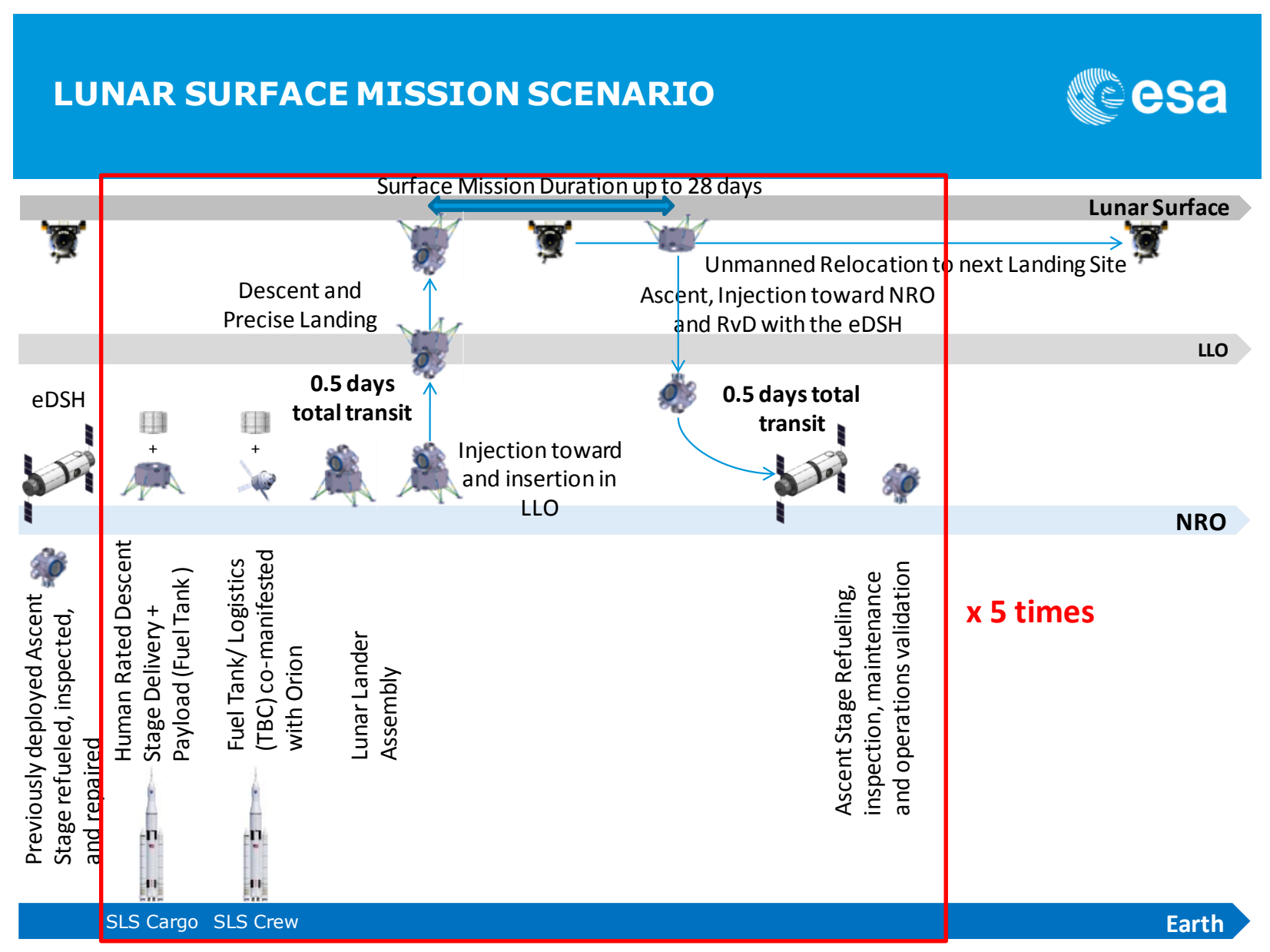

FIGURE 1 LUNAR SURFACE MISSION SCENARIO (NOTIONAL)

American Institute of Aeronautics and Astronautics 

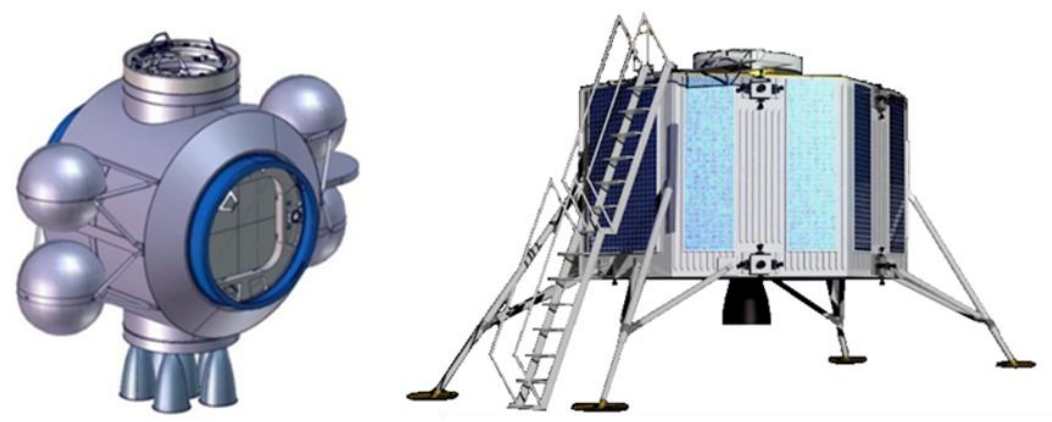

FIGURE 2 CONFIGURATION 1 ASCENT AND DESCENT MODULE (CONCEPTUAL)
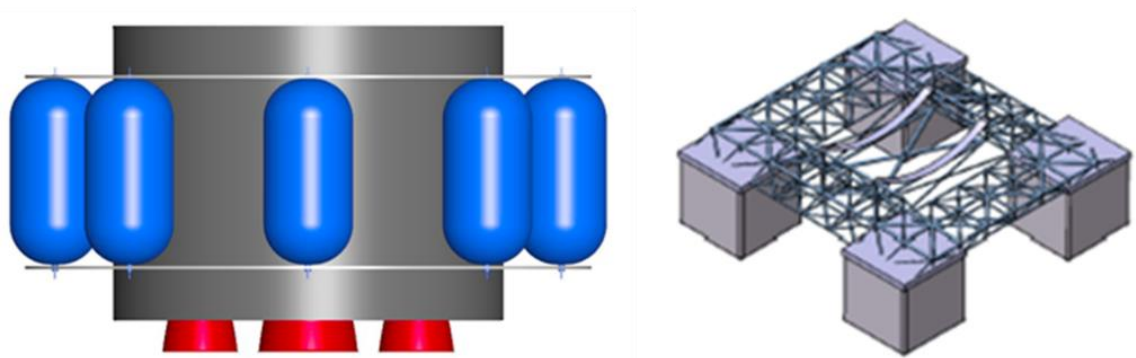

FIGURE 3 CONFIGURATION 2 DROP STAGE AND CRUSHABLE LANDING GEAR (CONCEPTUAL)

\section{TABLE 1 MAIN CHARACTERISTIC OF DESCENT MODULE}

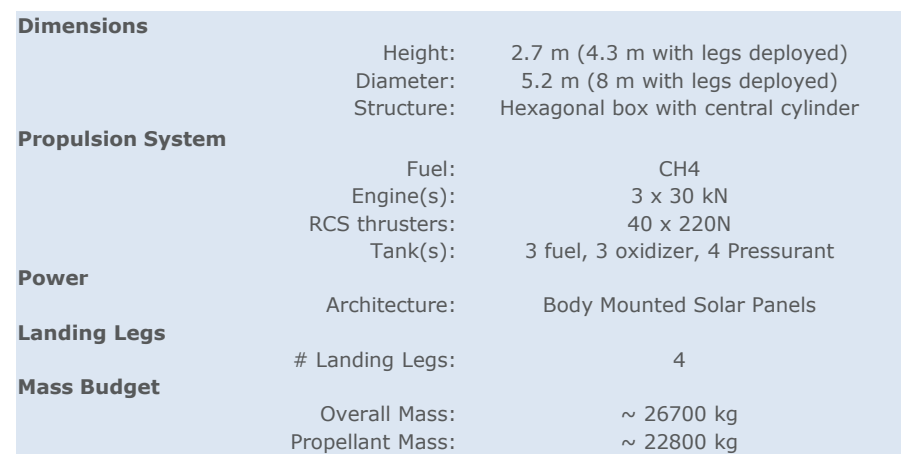

\section{B. Mars Ascent/Descent}

For Mars ascent and descent, NASA is considering a methane propulsionsystem that supports mis sion architecture goals for common engine development, a long-term surface In-situ Resource Utilization (ISRU) strategy, and soft cryogenic fluid management requirements. ${ }^{12}$ This will enable an in-space stage powered by a demonstrated workhorse engine, intended for boosting crew and cargo. The oxygen and methane propellant combination has the potential for high engine performance that will provide the required thrust for an entry and descent stage atthe destination and ascent propulsion for crew return. The LOxbased economy offers system compatibility that results in a lower outbound vehicle mass and greater payload-carrying capability to the Mars surface with ISRU at the destination to support return missions. ${ }^{3}$ NASA plans to demonstrate ISRU technologies that could enable propellant and consumable

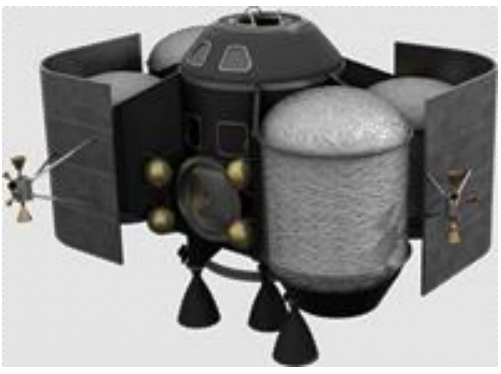

FIGURE 4 MARS ASCENT VEHICLE CONCEPT oxygen production from the Martian atmosphere. If successful, surface assets could be launched ahead of the crew to create oxidizer from the Mars atmosphere, prior to sending crew to the 
surface. In a long-term strategy, the use of soil processing technology and excavation techniques could allow missions to extract water from the indigenous res ources and thereby produce the propellant needed to propel an ascent vehicle to Mars orbit to rendezvous with an Earth return vehicle. This capability could also support future reusable lander strategies/architectures.

\section{Service Modules/Orbital Transfer Vehicle}

There are several other architectural elements where LOx/Methane propulsion systems can be utilized. A high performance service module for NASA's Orion vehicle or a crew taxi is within the thrustrange of this technology. A solar electric propulsion system, with a chemical stage for high thrust burns, is another option. These applications may be more tolerant of different thrust levels than a lunar lander.

\section{LOx/Methane Propellants Advantages and Disadvantages}

LOx/Methane is a critical and enabling technology for human space exploration. As a bipropellant propulsion system, LOx/Methane has some favorable characteristics for long life and reusability, which are critical to lunar and Mars missions. LOx/Methane propellants are non-toxic, non-corrosive, self-venting, and simple to purge. This alone enables much simpler and more reliable operations, particularly on the Mars surface. There is no extensive decontamination process required as with toxic propellants mono-methyl hy drazine (MMH)/nitrogen tetroxide (NTO). The high vapor pressure provides for excellent vacuumignition characteris tics for reaction control engines and main engines. The performance of LOx/Methane is better than current earth storable propellants for human scale spacecraft.

LOx/LCH4 provides the capability for future Mars exploration mis sions to use propellants that are produced in-situ on Mars. Entry, descent, and landing on Mars is significantly easier if $\sim 30$ MT of propellant for the Mars Ascent Vehicle is not required to be on-board, thereby reducing the MAV from 40 MT to 10 MT assuming oxy gen and methane are both produced in-situ on the Mars surface. Carbon dioxide fromthe Martian atmosphere, combined with proper amounts of water (found in the Martian regolith) and energy, yields both oxygen and meth ane. Methane production fromMartian resources requires less regolith mining than the equivalent thrust impulse production using hydrogen produced from Martian resources.

However, unlike current earth storable propellants, the cryogenic storage as pect of these propellants needs to be addressed. For zero boil-off, passive techniques using shielding and orientations to deep space, or refrigeration may be required to maintain both oxygen and methane in liquid forms, as they will absorb energy fromboth the s pacecraft and the environment. An integrated spacecraft design could take advantage of these properties by absorbing the heat leak with small amounts of liquid venting to vaporize some oxygen and methane. This vapor can then be used for fuel cells, life support, or attitude control. Liquid Methane is thermally similar to $\mathrm{O}_{2}$ as a cryogenic propellant, allowing for common components and thus providing cost savings as compared to liquid hydrogen ( $\left.\mathrm{LH}_{2}\right)$. In addition, its thermal management is more energy efficient due to the need to maintain temperatures at 90,111 K (LO2, LCH4 respectively) ins tead of the $23 \mathrm{~K}_{\text {of }} \mathrm{LH}_{2}$. Due to liquid methane having a $6 x$ higher density than hydrogen, it can be stored in much s maller volumes. However, the combination does have a $20 \%$ less efficient propulsive efficiency (Isp) than does $\mathrm{LOx} / \mathrm{LH}_{2}$. For human class landers and spacecraft, the increase in structure mas s for the larger volume of $\mathrm{LH} 2$ and the system complexity required by LH2 typically offsets much of the Isp gain at the vehicle level. This is in general not true for earth launch vehicle upper stages, though.

Commonality of fluid types will allow for some diverse redundancy by allow cross strapping of systems, e.g. O2 production can be used for life support, power, and propulsion. There is strong fluid commonality with other spacecraft subsystems such as Life Support $\left(\mathrm{O}_{2}\right)$ and Fuels Cells for power $\left(\mathrm{O}_{2}, \mathrm{CH}_{4}\right)$. This commonality can be used to save mass and increase redundancy.

\section{LOx/Methane Technology Areas}

The integrated propulsion systemis subdivided into the critical subsystems of pres surization, propellant tank thermal management, propellant acquisition, propellant feed, reaction control engines, and main engine, as shown in Figure 5. Each area is as sessed for performance needs, goals, technology solutions, status at each agency, and the gaps. Table 3 in the Appendix contains the spreadsheet summary inputs fromeach agency.

American Institute of Aeronautics and Astronautics 

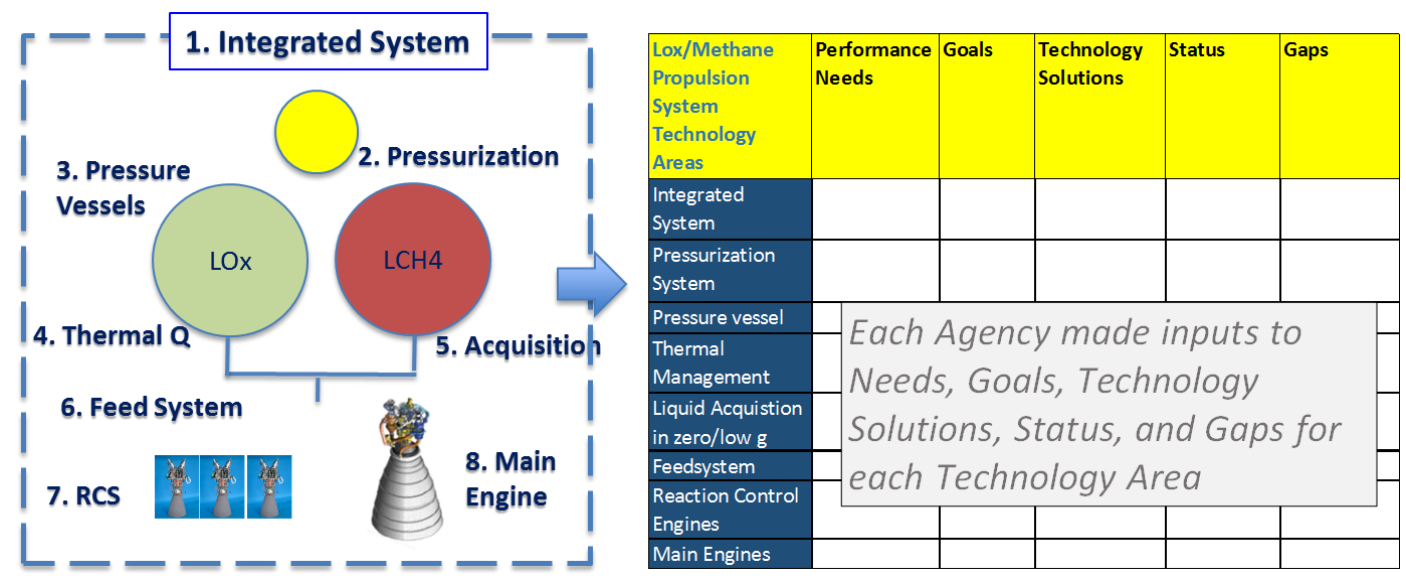

FIGURE 5 TECHNOLOGY AREA DIAGRAM AND EXAMPLE OF SPREADSHEET USED TO IDENTIFY GAPS

\section{Current Status of LOx/LCH4 Technology at Each Agency}

Each of the agencies has conducted work on LOx/Methane propulsion systems. The teams reached out to subject matter experts with experience in LOx/Methane propulsion. The group of subject matter experts reviewed the concept and initial sizing of a lunar lander to extract the required key needs and performance parameters. The team reviewed concepts for vehicles from International Architecture Working Group (IAWG) GER 2.0 architecture and the exis ting GTDM and portfolio entries to extract performance metrics.

Each international agency then provided a status of LOx/Methane technology work within their agency. All of the participating agencies have conducted substantial technology development of Liquid /Oxygen and Methane propulsion systems. The work has included pressurization systems, cryogenic fluid management of liquid oxygen and methane, fluid feed systems, reaction control engines, and main engines. The work ranges fromignition studies, cryogenic fluid management of methane and oxygen, LOx/Methanereaction control engines, and full-up pressure-fed and pump-fed engines.

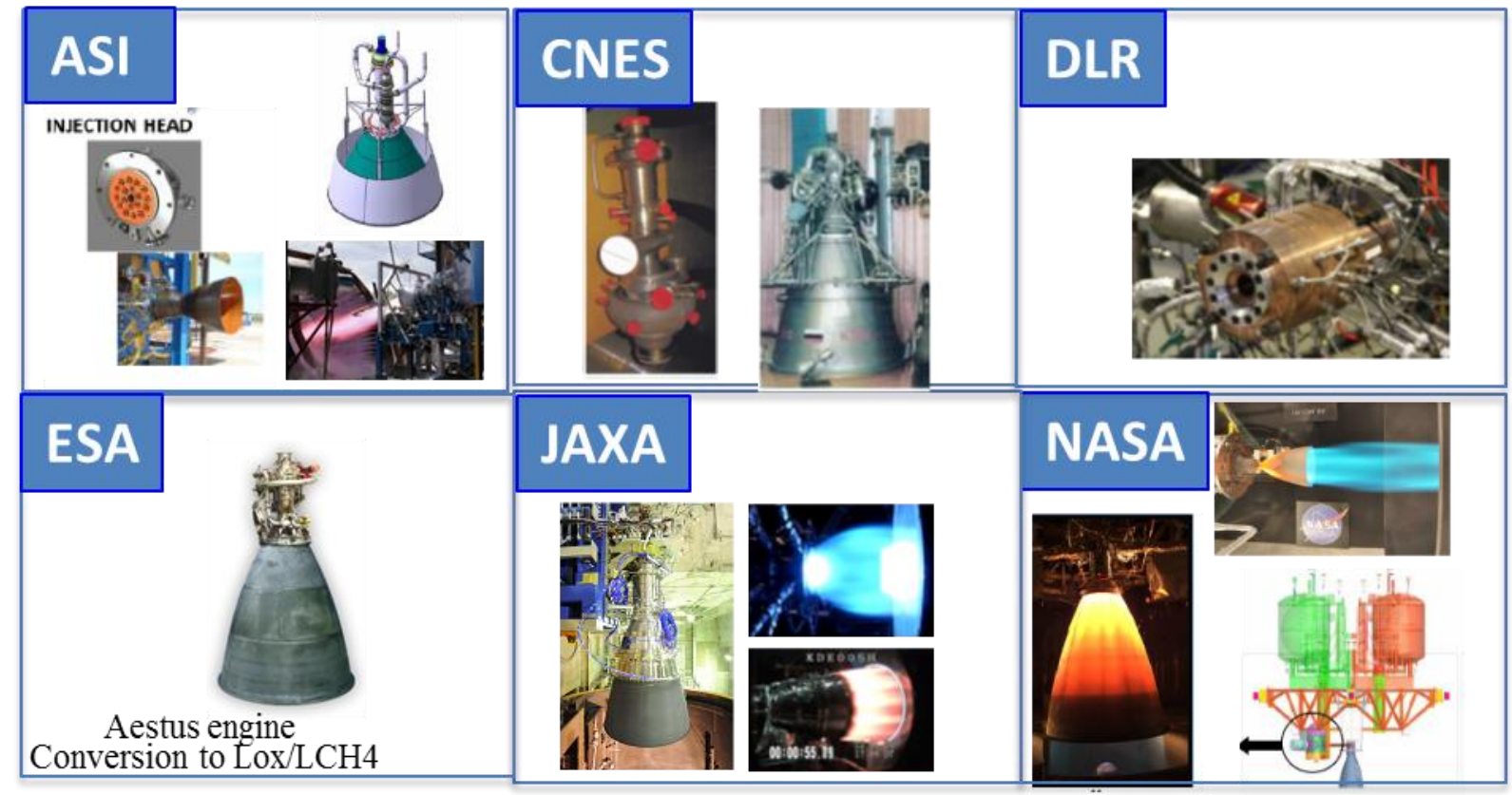

American Institute of Aeronautics and Astronautics 


\section{A. ASI (Agenzia Spaziale Italiana) - LOx-Methane propulsion in Italy - Synthes is for $\mathrm{LOx}_{-} \mathrm{CH}_{4}$ Working}

Group Report at ISECG

ASI started its commitment on LOx-Methane technologies more than 15 years ago, initially with small res earch thrust chambers tested in a dedicated facility in Italy. In the context of the Lyra programfor the study of evolutions of the Vega launcher, ASI supported a significant activity of design and technology development dedicated to the realization

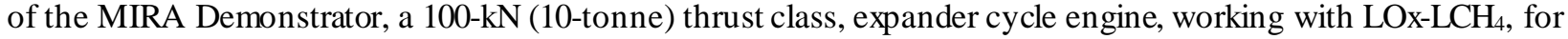
the a new upper stage of Vega. The program encompassed the development of critical components working with methane fuel, such as the thrust chamber injector head and the fuel turbo-pump. The demonstrator, developed in cooperation with Russian industry under a dedicated agreement with Roscosmos, was successfully tested in 2012 at level of Thrust Chamber Assembly, ${ }^{4}$ and then tested again in May 2014 at the complete engine level, with more than 11 tes ts performed up to full operating condition and accumulating more than $600 \mathrm{~s}$ of firing. ${ }^{5}$ Dedicated activities of development and testing have been performed on liquid methane fuel turbo-pump bearings working in liquid methane ${ }^{6}$, supported by the realization of a dedicated test facility in Italy.

In the context of international cooperation with JAXA, ASI is supporting further activities specifically dedicated to investigating the methane thermal behavior, characterizing bearings working in liquid methane, and designing a regenerative thrust chamber in the $100-\mathrm{kN}$ (10-tonne) class which is to be tested in Italy.

Anotherinitiative is the design of small methane thrusters to be applied as a potential reaction control systemof the launcher stage, eventually integrated with a primary propulsive system. A preliminary test campaign has successfully been completed.

The Italian Aerospace Research Center, CIRA, is developing the 'Hyprob' research program, specifically dedicated to combustion phenomena studies and breadboard testing, up to the design of a medium scale, 30-kN (3-tonne thrust class) regenerative thrust chamber; the programincludes the realization of test facilities at both laboratory level and thrust chamber ass embly (up to $100-\mathrm{kN}$ (10-tonne class). ${ }^{7}$

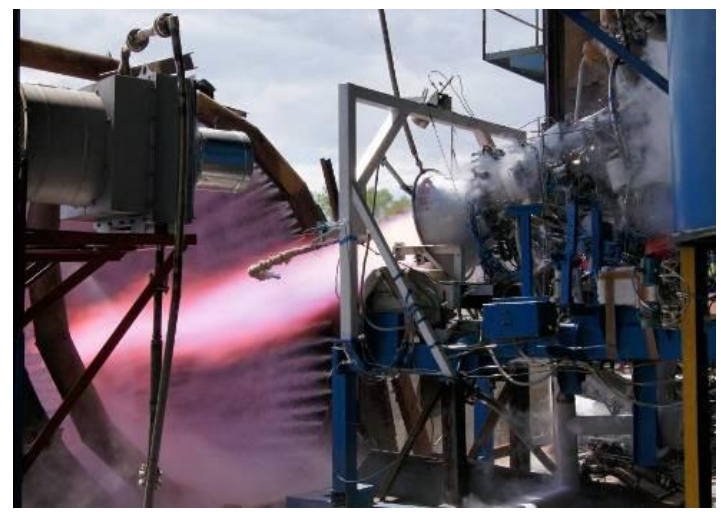

FIGURE 9 MIRA ENGINE DEMONSTRATOR TESTED MAY 2014

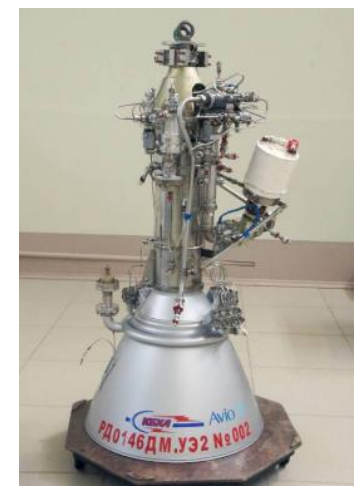

FIGURE 8 MIRA THRUST CHAMBER

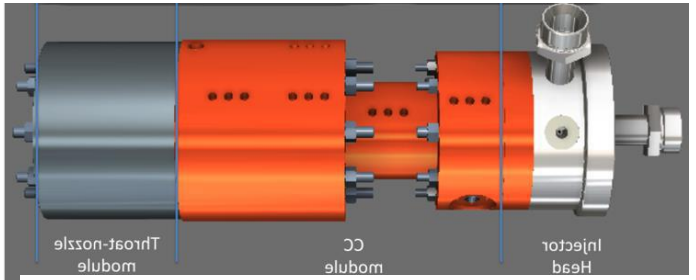

FIGURE 6 SINGLE INJECTOR RESEARCH THRUST CHAMBER

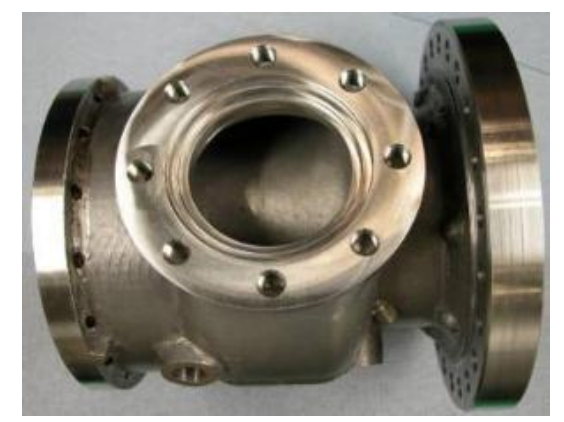

FIGURE 7 MIRA CH4 TURBINE MANIFOLD PRODUCED BY DMLS TECHNIQUES

American Institute of Aeronautics and Astronautics 
B. CNES (Centre national d'études spatiales)

ForCNES, systems analysis of LOx/Methane propulsion is a critical gap area that has to be addressed._CNES regularly trades LOx/Methane propulsion with other alternatives $\left(\mathrm{LOx}_{\mathrm{LH}}\right.$, non-toxic storable propellants, etc.) to identify the best choices for each mis sion under consideration. Optimization is taken into consideration for an overall stage architecture (mas ses, volumes, technical performance, as well as financial considerations). More generally s peaking, opportunities for LOx/Methane propulsion devices are studied through an overall system analysis, including topics such as:

- Quality and availability of methane propellant

- Type of pres surization

- Ranges of operating domains for the engines

- Requested operations for re-ignitions capabilities

Relative to technology, no complete engine has been developed under a CNES program to date. Nevertheless, engine tests have been achieved on KVD1 Rus sian en gine during a French - Rus sian cooperation. ${ }^{8}$ Engine studies (Phase A studies) have als o been performed at a high level of thrust $(2000 \mathrm{kN}, 200 \mathrm{t})$ with Rus sian colleagues, but no parts were manufactured at this scale. ${ }^{9}$

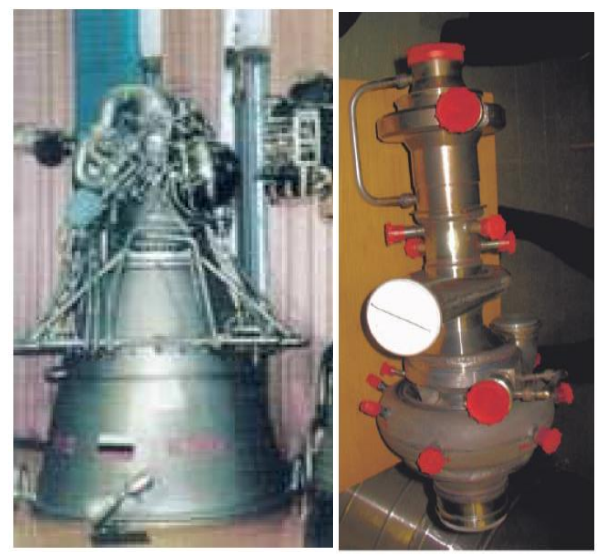

FIGURE 10 KVD1 ENGINE WITH ITS MODIFIED TURBO PUMP FOR TESTS

Research \& Development activities are also being performed in parallel with several designs, manufacturing and testing at subsystem level (combustion tests and simulation capabilities including high-frequency -HF- instability analysis, pump and inducer performances, for example). ${ }^{10}$

French capabilities are also currently being developed for cryogenic propellant management in tanks during various dynamic and thermal phases, resulting in a capability to simulate, predict and analyze propellant behavior under anticipated conditions.

The current main objective for CNES with French industry support is to prepare a LOx/ Methane low cost, gasgenerator engine demonstration at 1000-kN (100 t) thrust level before 2023. ${ }^{11}$

Before this phase, investigations at the engine level will be performed on a technology maturation platform (10-kN scale - bleed expander cycle). These evaluations are in progress, with ignition tests by the end of 2015 as an initial planned step. Moreover, the capability of current $\mathrm{LOx} / \mathrm{LH}_{2}$ engines to operate with LOx/Methane is also being addressed.

\section{DLR (Deutsches Zentrum für Luft- und Raumfahrt)}

A few launcher systems tudies have been performed atDLR in the past on reusable and expendable stages using LOx/ Methane propulsion. A partially reusable system for a Liquid Fly-Back Booster (LFBB) has been preliminarily designed for both methane and kerosene as propellants in combination with LOx. ${ }^{12}$ A high performance staged combustion rocket engine has been conceptually designed to reach a performance level comparable to the Russian RD-180 motor of Energomash. The study showed that the advantage of the higherenergetic content of methane was 
counterbalanced by an increased motor mass and an increased booster size, hence higher aerodynamic drag and increased system mass. The payload performance of the reusable kerosene and methane booster were found almost identical with some edge for kerosene ${ }^{13}$.

Experimental and numerical research activities - Experimental research activities conducted at DLR have focused on the combustion and ignition of LOX/CH4 at both a sub-scale for higher thrust engines, as well as at full-scale for RCS thrusters. The table below summarizes these activities and main findings.

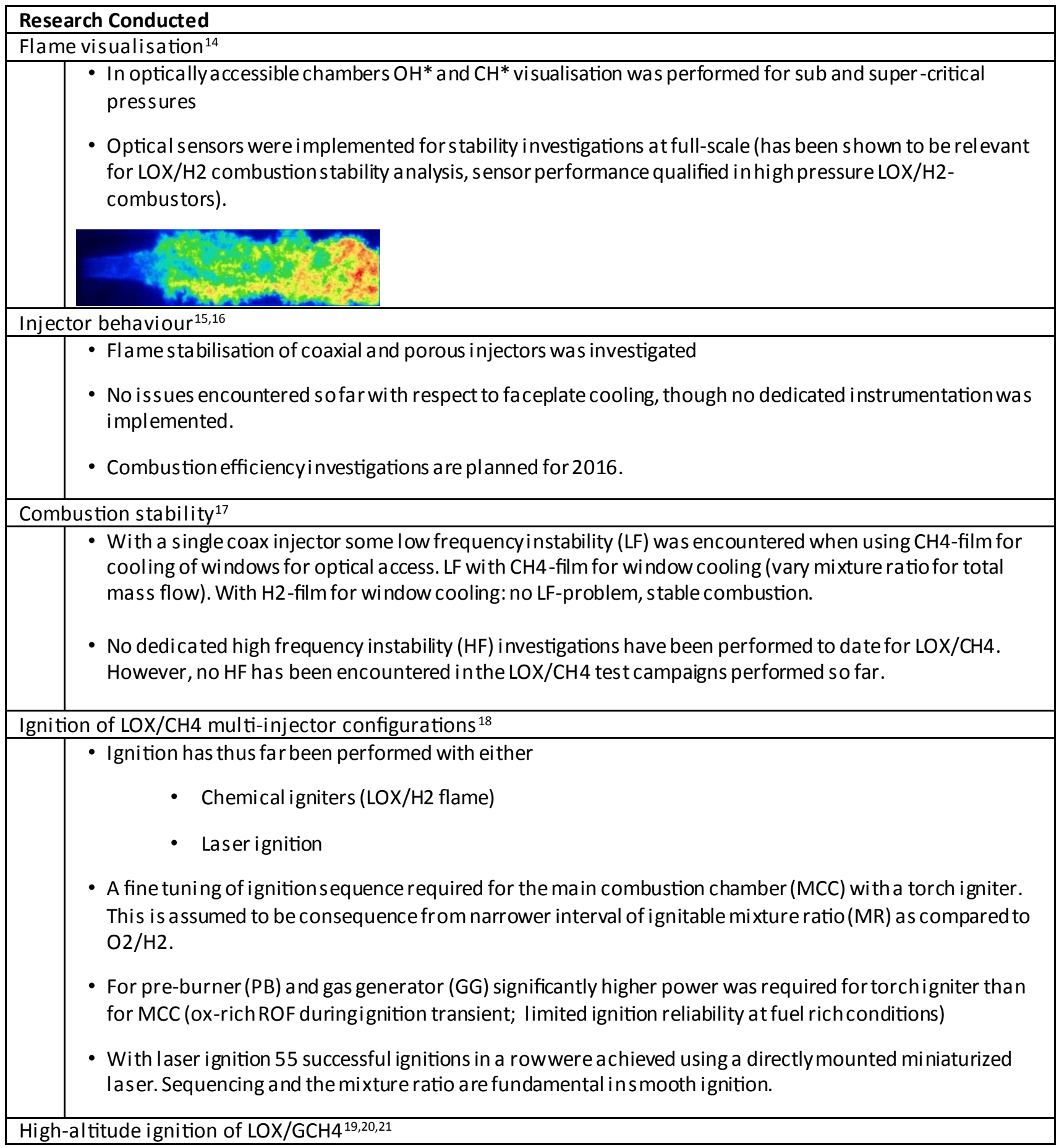

American Institute of Aeronautics and Astronautics 


\begin{tabular}{|c|c|}
\hline & $\begin{array}{l}\text { - Laser ignition of a full-scale } 200-400 \mathrm{~N} \text { RCS chamber was performed to determine the mi nimal ignition } \\
\text { energy and demons trate the feasibility of I laser ignition. } \\
\text { - Pre-ignition flow conditions in the chamber were visualised. Phenomena observed included supersonic } \\
\text { gas eous flow with a ba rrel flow a nd Mach shock and LOX fla shing. }\end{array}$ \\
\hline \multicolumn{2}{|r|}{ LOX/Methane pre-burner applications } \\
\hline & $\begin{array}{l}\text { - Regenerative cooling with methane } \\
\text { - Film cooling with methane was performed } \\
\text { - No sooting issues experienced up to now. No thermal radiation in plumes was visible and no deposition on } \\
\text { chamber walls was observed. }\end{array}$ \\
\hline
\end{tabular}

D. ESA (European Space Agency)

LOX/methane propulsion for ESA Launchers - Synthesis for LOx-CH 4 Working Group Report @ ISECG: LOx/Methane propulsion has been considered for ESA launchers since the mid-2000's as a potential path to reducing the cost of access to s pace. Launcher system stu dies were carried out, mostly limited to concepts and performance rough estimates. LOx/Methane objectives have been embedded on certain enginetechnology demonstrators, often in dual use with $\mathrm{LOx} / \mathrm{LH}_{2}$, mainly for the characterisation of combustion phenomena.

In the meantime, significant advances have been developed in $\mathrm{LOx} / \mathrm{CH}_{4}$ propulsion by the national space agencies of several important Member States of ESA, mainly Germany, France and Italy. Most of these projects have at times involved cooperation with a partner outside Europe.

In the wake of the decision to develop Ariane 6 based on $\mathrm{LOx} / \mathrm{LH}_{2}$ and solid propulsion, ESA is evaluating $\mathrm{LOx} / \mathrm{CH}_{4}$ propulsion for the longer term, along with reus ability schemes, with the specific objective of drastic cost reductions for access to space. This effort leans on some of the results of the projects in Germany, Franceand Italy, and is closely aligned to the potential evolution of the European launchers. The as sociated target engines are in the categ ories of a $1000-\mathrm{kN}+$ gas generator and a 100-kN expander cycle.

Another way to quickly address the need displayed in the ISECGGap As sessment working group for 30-kN propulsion could be to adapt the existing Aestus engine (currently an Ariane 5 storable bi-propellant engine) to $\mathrm{LOx} / \mathrm{CH}_{4}$. This pressure-fed engine would offer the advantage of simplicity compared to pump-fed engines. However it has to be noted that this option is not being worked out currently at ESA and would require the support of certain Member State national space agencies. If the mission needs were more in the direction of large propellant loadings, a pump -fed engine may be more appropriate. In that case the options would be around a $\mathrm{LOx} / \mathrm{CH}_{4}$ expander-cycle engine, probably derived from a current $\mathrm{LOx} / \mathrm{LH}_{2}$ engine demonstrator project and certain Member State national programs.

\section{E. JAXA (Japanese Aerospace Exploration Agency)}

The research and development of liquid natural gas (LNG) engines have been carried out in Japan, and several engines have been designed, manufactured and tested. Table 2 shows the summary of LNG engines in Japan.

\section{TABLE 2 SUMMARY OF LNG ENGINES IN JAPAN}




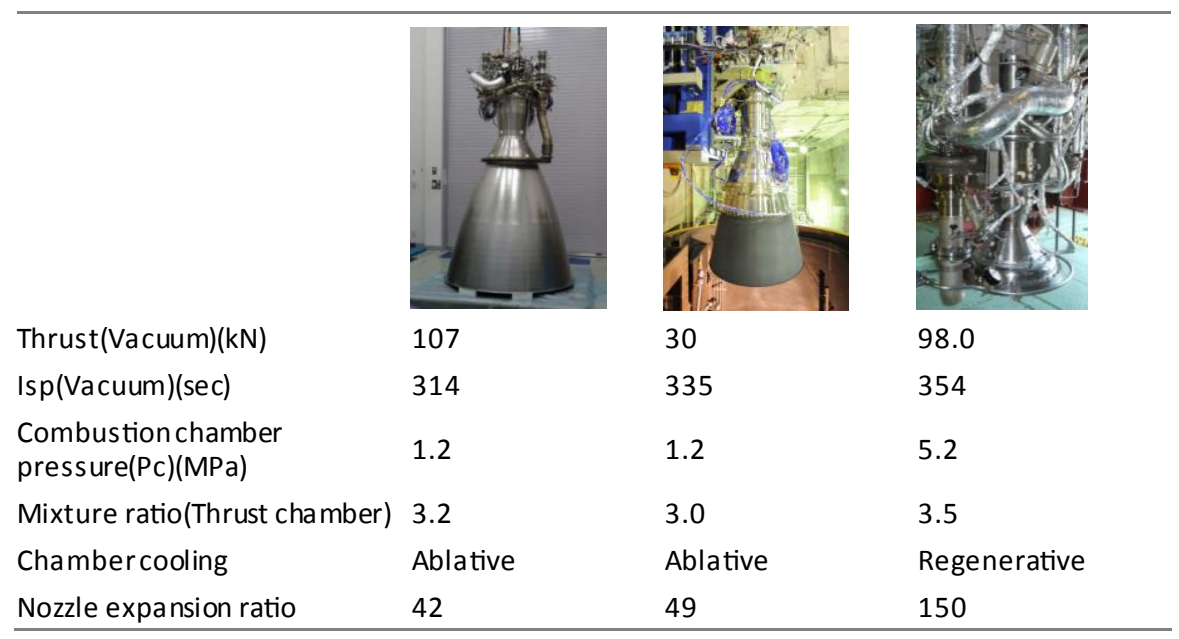

A 100-kN class LNG rocket engine, named LE- $8^{22}$, had been developed by Japan Aerospace Exploration Agency (JAXA) and IHI Aerospace Co., Ltd. (IA) until 2009 as the second stage engine of the GX rocket and successfully completed more than 2000 seconds of its firing tests. Through the development of the LE-8, the knowledge for the design of LNG rocket engines was accumulated and the feasibility of LNG rocket engines was confirmed.

Although almost all the technical is sues of the LE-8 engine were checked and solved during the development period, the performance of the LNG engine was not confirmed under a flight condition, i.e. vacuum. After the development of the LE-8, JAXA and IA started stu dies of an LNGengine for the purpose of obtaining performance data with a high altitude test stand (HATS). The thrust level was selected to be $30 \mathrm{kN}$ for an experimental engine in this research, because a 30-kN class engine was considered useful for various future spacecraft, and its small size was suitable for the HATS. Five firing tests with a total of 122 seconds were carried out and the functions and performance of the engine were confirmed under high altitude conditions ${ }^{23,24}$.

The LE- 8 and the 30-kN clas s engines consist of an ablative chamber and a liquid-liquid impinging type injector, making the engine system simpler and reducing the cost. Although the value of $\mathrm{I}_{\mathrm{sp}}$ has increased as a result of the improvement on the design of chamber and injector, it seems to have reached close to the upper limit. Aimed at improving the combustion efficiency drastically, another LNG engine which has a regenerative cooling chamber was designed and demonstrated in a ground test facility in parallel with the HATS te st. The activity was carried out by the IHI Corporation (IHI) as in-house research program. The test series of the engine was successfully completed and its $\mathrm{I}_{\mathrm{sp}}$ reached to approximately $350 \mathrm{sec}^{25,26}$

Although JAXA has been carrying out the R\&D activities on LNG engines, Japanese LNGengines have not been used for an actual flight. The reason is that the performance and characteristics of current LNG rocket engines do not have enough advantages compared with other liquid rocket engines. Therefore, JAXA has decided to improve the performance of Japanese LNGengines drastically and is planning to apply the engine to future space transportation sys tems (e.g. a reusable liquid rocket booster and an orbital transfer vehicle). Currently, to achievehigher performance, JAXA is carrying out a research activity on LNGengines focusing on a regenerative cooling type engine. For example, JAXA is planning single and multi-element firing test, heat transfer measurement test for tube flow, etc. ${ }^{27}$.

\section{F. NASA}

NASA has conducted systemlevel propellant trade studies that identified LOx/Methane as a top in-s pace propellant for human spacecraft. ${ }^{28} \mathrm{LOx} / \mathrm{Methane}$ architectures support in-situ production of propellants on the Mars surface for ascent vehicles. ${ }^{29}$ NASA has been focused on the development of technologies at the systemand component level for LOx/Methane cryogenic propellant management, primarily through technology projects such as the Propulsion and Cryogenic Advanced Development (PCAD) and Cryogenic Fluid Management (CFM) since the mid 2000's. ${ }^{30}$ At the integ rated systemlevel, under the PCAD project, NASA has conducted integrated testing of a cryogenic feed sys tem, RCS engines, and main engine for a pressure-fed $\mathrm{LOx} / \mathrm{LCH}_{4}$ systems at altitude using a heavy weight vacuum jacketed tank and lines. From2011-2014, the Advance Exploration Systems projectconducted terrestrial flight testing of an integrated LOx/Methane system test bed on the Morpheus Lander. The Morpheus systemconsisted of blowdown helium pressurized aerogel insulated aluminum tanks, an integrated reaction control system(RCS) and a throttling main engine. The terrestrial flights demonstrated a LOx/Methane system integrated with guidance navigation and control (GNC). 
Because of the cryogenic propellant temperat ures, more helium is required to pressurize cryogenic propellant tanks. For a lightweight pressurization system, GHe is stored at high density and then warmed for pressurization. The Apollo lunar lander utilized cold, supercritical He storage and a fuel heat exchanger (HEX) to improve performance. Launch vehicles currently may use storage of GHe tanks within the propellants tanks to improve storage density. NASA has recently conducted tests of a carbon overwrapped pressure vessel (COPV) at cryogenic temperatures for use in a cold, high-density GHe pressurization system. ${ }^{31}$

In 2009 under the CFM project, a $1.2 \mathrm{~m}$ diameter spherical tank was used to demonstrate insulation and fluid performance in various environments as sociated with transit to a lunaror Martian outpost ${ }^{32 \mathrm{~b}}$. More recently, a zeroboil-off (ZBO) system for liquid oxygen was demonstrated using a $1.2 \mathrm{~m}$ x $1.5 \mathrm{~m}$ cylindrical tank and a flight-like cryocooler $^{33}$. Cryocoolers up to $\sim 20 \mathrm{~W}$ at $90 \mathrm{~K}$ have been demonstrated in ZBO mode. Larger scale cryocooler development is in work with up to an order of magnitude increase in cooling power. Investigations into the control of pres sure of sub-cooled liquid methane revealed that extreme care must be taken to achievecooling through JouleThomps on devices due to the formation of meta-stable conditions that can be achieved. ${ }^{34}$ Liquid acquisition device bubble point and flow testing and characterization were accomplished. ${ }^{35,36,37}$ The Radio Frequency Mass Gauge (RFMG) has been developed and demonstrated as a mass gauge in micro-gravity for various propellants, showing promis ing accuracy. ${ }^{38},{ }^{39}$ Vacuumchamber testing of cryogenic feed systems ${ }^{40}$ with multiple RCS engines and single main engine have been conducted. On the Morpheus vehicle, a Joule-Thompson device was used to pre-chill the transfer lines of the auxiliary control propulsion system. ${ }^{41}$

Currently, the Evolvable Cryogenics project is developing a flight rated version of the Radio Frequency Mass Gauge for inclusion in the cryogenic subsystem of the Robotic Refueling Mis sion $3 .{ }^{42}$ Work is on-going in the testing and development of flow boiling correlations for heat transfer in hydrogen, oxygen, and methane. Several other topics within the Evolvable Cryogenics project, while using a hydrogen boundary, will als o be useful for oxygen and methane systems. These include the development of Multilayer Ins ulation (MLI) design details (such as what is the best way to seam MLI thermally) and large scale applications of MLI. Other work is focusing on the liquefaction systemfor handling in-situ generated oxygen within lander propellant tanks. Much work on the modeling of cryogenic propellants and two-phase systems using both commercial and in-house codes continues. From the simplest multinode models to complex computational fluid dynamics (CFD) analysis, various effects and couplings such as two phaseflow and heat transfer mechanisms are being investig ated computationally. To investig ate various fluid mixing phenomena with cryogenic simulants, the Zero Boil-off Transfer (ZBOT) payload is currently being developed for the ISS Microgravity Science Glovebox ${ }^{43}$. For slosh damping, tests have been conducted on baffles in LOx/Methane propellant tanks. ${ }^{44}$

Several smaller funding sources (such as Small Business Innovative Research, SBIR, projects) are focusing on possible advances in the state of the art, such as spherical cryogenic-rated composite vessels, lightweight vacuum jackets, and advanced soft vacuuminsulation systems. Methods of reducing structural loads are being looked at from several angles such as vapor cooling and sacrificials tructures. However, for long duration storage systems, it is key that thermal problems be considered in the design of the stage structure. This will lower the heat load into the propellant significantly reducing cryocooler lift (and mass) requirements.

NASA has conducted tests for $\mathrm{LOx} / \mathrm{LCH}_{4} \mathrm{RCS}$ and main engines. RCS engines at thrust levels of $88 \mathrm{~N}\left(20 \mathrm{lb}_{\mathrm{f}}\right), 444$ $\mathrm{N}\left(100 \mathrm{lb}_{\mathrm{f}}\right)$, and $3.8 \mathrm{kN}\left(870 \mathrm{lb}_{\mathrm{f}}\right)$ have been tested over a range of gas-gas to liquid-liquid conditions. ${ }^{45}, 46,{ }^{47}$ Both ablative and a regenerative cooled RCS engines were successfully design and tested. A Pres sure-fed 24.5-kN (5500lbf) film-cooled/ablative engine for lunar ascent has also been tested at vacuum conditions. Tests with a 129:1 ratio nozzle demonstrated performance values that, when extrapolated for a 150:1 ratio nozzle, were within $2 \%$ of target $355 \mathrm{~s}$ Isp.

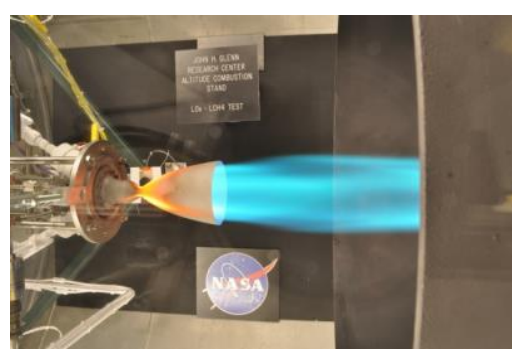

FIGURE 13 AEROJET 100-LBF LOX/LCH4 REACTION CONTROL ENGINE IN ALTITUDE TEST AT GRC.

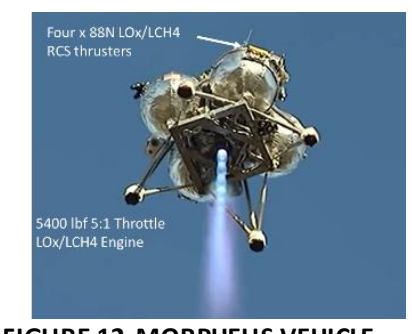

FIGURE 12 MORPHEUS VEHICLE WITH LOX/LCH4 INTEGRATED MAIN ENGINE AND RCS

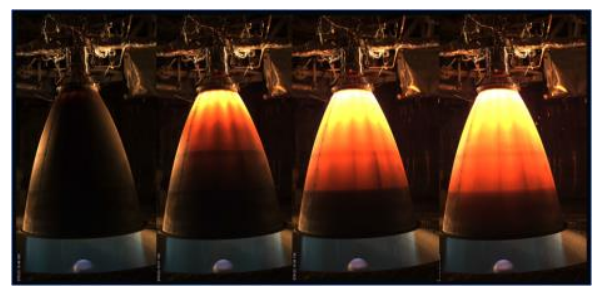

FIGURE 11 AEROJET LOX/LCH4 ASCENT MAIN ENGINE DURING ALTITUDE TESTING AT WSTF

American Institute of Aeronautics and Astronautics 
Pressure-fed LOx/Methane engines, both 24-kN (5400 lb $\left.\mathrm{b}_{\mathrm{f}}\right)$ and 8.8-kN (2000 $\left.\mathrm{lb}_{\mathrm{f}}\right)$ scales and with ablative and filmcooled chambers capable of throttling, were operated on the Morpheus test bed at sea level..$^{48}{ }^{49}$ Some limited combustion chamber cooling tests using heated tubes and engine tests have been conducted for regenerative-cooled engines. Injectors designed for use in pump-fed engines for LOx/Methane, such as gaseous methane and liquid oxygen swirl coax, have also been conducted. ${ }^{50,51}$

NASA is continuing to build upon prior methane engine development experience. This includes testing of pressurefed and pump-fed thruster and engine designs with the potential for scalability to achieve the approximately $88 \mathrm{kN}$ to $155 \mathrm{kN}\left(20,000\right.$ to $35,000 \mathrm{lb}_{\mathrm{f}}$ ) of thrust, high performance, and throttling capability needed for larger descent/ascent landers on Mars. The total thrust required would be achieved by teaming engines to required performance commensurate with the final human scale lander. Currently, small-scale pressure fed $\left(17-\mathrm{kN}\left(4,000-\mathrm{lb}_{\mathrm{f}}\right)\right)$ and largescale pump fed $\left(111-\mathrm{kN}\left(25,000-\mathrm{lb}_{\mathrm{f}}\right)\right)$ engine components are being tested, with the goal of performing integrated breadboard engine testing at both scales with in the next year. The breadboard engines will provide a test bed capability for developing the component and system technology required to ultimately develop and certify a large methane engine for future human Mars Missions.

When used in combination with the primary propulsion for ascent, descent and transit, an integrated Lox/Methane RCS approach delivering on the order of $444 \mathrm{~N}$ to $4 \mathrm{kN}$ (100 to $1000 \mathrm{lbf}$ ) thrust at 325 seconds $\mathrm{I}_{\mathrm{sp}}$ s upports the mis sion architecture goals for common engine development and compatibility. Within NASA advanced additive manufacturing techniques are being applied to thruster as sembly and component technology development to improve performance, reduce fabrication processes and compress schedule. Additionally, the application of additive manufacturing has allowed engineers to more readily incorporate features that facilitate component testing and accelerate the learning curve on engine behavior.

\section{Technology Gaps}

The gaps have been identified wherein the technology needs exceed the current technology state. These gaps can either be worked on jointly in a partnership or can be spread-out among different agencies. In addition, some gaps such as main engine technology may require multiple agency partners to have the most effective results.

- Develop a throttle-able regenerative-cooled pump-fed and/or pressure-fedengines to address gap for throttling (5:1 - 10:1), 360-365 sec, and for regenerative-cooled engines in the $30-100 \mathrm{kN}$ range. Regenerative cooling provides a performance increase over fuelfilm cooling. For landers, throttling is required. The combination of these two requirements, as well as the application dependent need for both pres sure-fed and pump-fed engines results in a significantgap.

- Develop 100 to 220-N RCS thrus ters with integrated cryogenic feed sys tems to address es gap for thruster size/cost and then to evaluate GNC impulse bit and thrust requirements. This smaller size thruster has notbeen fully developed and tested. As part of the RCS engine technology, systemintegration analys is us ing GNC vehicle models needs to demonstrate that GNC impulse bit and thrust requirements can be met with LOx/LCH4 thrusters.

- Develop long duration reliable cryogenic refrigeration sys tems capable of maintaining zero-boil- off and performing liquefaction of in-situ produced propellants (several hundred watts at $\sim 90 \mathrm{~K}$ ). This size cryocooler is required for future Mars surface operations. The use of proving grounds will be critical to the demonstration of this technology.

- Develop composite cryogenic tanks with focus on spherical geometry to addresses gapin propellant tank technology. Cylindrical cryogenic all-composite tanks have seen some development, but not allcomposite cryogenic tanks in a spherical geometry. A spherical tank geometry offers advantages in the reduction of surface area for thermal storage improvements and ease of vacuumjacketing. Mass performance, heliumpermeability and off-gassing will be key performance factors.

- Develop high performance pressurization systems that improve storage density and reduce mass to address gap for use with cryogenic propellants. Significant mass savings can be obtained by technologies such as the use of cold (high density) helium storage and heat exchangers to warmhelium 
prior to propellant tank pressurization or the use of autogenous pressurization, but that there is gap in the components and models for use with LOx/methane.

- Conduct extended duration thermal vacuum testing of integrateds ystem to address gap of integrated system tes ting in thermal vacuum environment. Component level tests, such as tanks with MLI, have been conducted in thermalvacuum to simulate s pace, however systemlevel tests in a thermal vacuum environment have not been conducted. This would includeGHe pressurization, propellant tanks, feed system, and engines.

- Fly a zero-g cryogenic liquidacquisition experiment in space, such as on the ISS or in a cis-lunar location to address gap of lack of demonstration of $\mathrm{LOx} /$ methane in these conditions. This experiment would provide critical data, scaling, and model validation which can be used for the design of future vehicles. This can be combined with a test vehicle flight.

- Fly a test vehicle in space as a technology infusion mission to demonstrate integratedLOx/Methane propulsion systems to address gap of no in-space LOx/Methane flight experience. Lack of s pace flight experience is an impediment to programacceptance of the risk.

\section{Conclusion}

Lox/Methane (or Liquefied Natural Gas) is an enabler for future exploration with in-situ propellant production, improved performance, improved reu sability and elimination of toxicity is sues for surface operations, and fluid commonality. The teamidentified common technology is sues and gaps that can be addressed in the near term. All of the partners find value in continued investment through partnerships. The teamhopes that technology implementers at each agency will be able to use this to help focus on critical needs. 


\section{References}

${ }^{1}$ T Polsgrove et al., (2015), “Mars Ascent Vehicle Design for Human Exploration,” AIAA Space 2015, Pasadena, CA.

${ }^{2}$ A.D. Cianciolo, K Brown. (2015) "Impact of Utilizing Phobos and Deimos as Waypoints for Mars Human Surface Missions" AIAA Space 2015, Pasadena, CA

${ }^{3}$ L Toups, S Hoffmann, K Brown. (2015). "Transportation-Driven Mars Surface Operations Supporting an Evolvable Mars Campaign", IEEE Aerospace Conference, Big Sky, MT, March 7-14, 2015.

${ }^{4}$ Gurtovoy, Kosmacheva, Rachuk, Scarpino, Carapellese, Biagioni, de Lillis, D' Aversa - Development of Thrust Chamber Assembly for LOX LNG Expander Cycle Liquid-Propellant Rocket Engine - EUCASS 2013

${ }^{5}$ Gurtovoy, Lobov, Rachuk, Arione, Bellomi, Carapellese, Caggiano, Liuzzi, Rudnykh, de Lillis, D' Aversa, Pellegrini - Development of LM10Mira LOx/LNG Expander Cycle Demonstrator Engine - IAC-15-C4.1.7

${ }^{6}$ Rudnykh, Caggiano, Liuzzi, Kravchenko, Chembartsev, de Lillis, D’ Aversa - Fuel Turbopump development for the LM10-MIRA LOX-LNG expander cycle engine in the frame of LYRA program - EUCASS 2013

${ }^{7}$ Salvatore, Battista, De Matteis, Ceccarelli - An overview of experimental activities and results addressing the development of LOx/LCH4 rocket engine technology in the Italian HYPROB program - IAC-14.c4.3.1

${ }^{8}$ French Russian activities on LOX / LCH4 area IAC $-06-\mathrm{C} 4.3 .7$

${ }^{9}$ LOX / methane studies for fuel rich preburner AIAA 2003 - 5063

${ }^{10}$ Oxygen - methane combustion activities in the In Space Propulsion programme EUCASS 2011 (European Conference for Aerospace Sciences)

${ }^{11}$ The future of Liquid Propulsion : french activities IAC $-15-\mathrm{C} 4.1 .4$

${ }^{12}$ Burkhardt, H.; Sippel, M.; Klevanski, J.; Herbertz, A.: Comparative Study of Kerosene and Methane Propellants for Reusable Liquid Booster Stages, AIAA 2002-5235, 2002

${ }^{13}$ Burkhardt, H.; Sippel, M.; Klevanski, J.; Herbertz, A.: Comparative Study of Kerosene and Methane Propellants for Reusable Li quid Booster Stages, AIAA 2002-5235, 2002

${ }^{14}$ Cuoco, F., Yang, B., Bruno, C., Haidn, O.J., Oschwald, M.: Experimental Investigation on LOx/CH4, AIAA 2004-4005, 40 ${ }^{\text {th }}$ JPC, Fort Lauderdale, Florida, 2004

${ }^{15}$ Lux, J., Haidn, O.J.: Flame Stabilization in High-Pressure Liquid Oxygen/Methane Rocket Engine Combustion, Journal of Propulsion and Power, Vol. 25, Jan/Feb 2009

${ }^{16}$ Yang, B., Oschwald, M.: Atomization and Flames in LOX/H2 and LOX/CH4-Spray, Journal of Propulsion and Power, Vol. 23, Jul/Aug 2007

${ }^{17}$ Lux, J., Suslov, D., Bechle, M., Oschwald, M.: Investigation of Sub- and Supercritical LOX/Methane Injection Using Optical Diagnostics, AIAA 2006-5077, 42nd JPC, 2006

${ }^{18}$ Börner, M., Manfletti, C., Oschwald, M.: Laser Re-Ignition of a Cryogenic Multi-Injector Rocket Engine, 6th EUCASS, 2015

${ }^{19}$ Manfletti, C.: Laser Ignition of a Research 200 N RCS LOx/GH2 and LOx/GCH4 Engine, AIAA 2012-4132, 48th JPC, 2012

${ }^{20}$ Manfletti, C.: Laser Ignition of an Experimental Cryogenic Reaction and Control Thruster: Pre-Ignition Conditions, Journal of Propulsion and Power, Vol 30, pp. 925-933, 2014

${ }^{21}$ Manfletti, C.: Laser Ignition of an Experimental Cryogenic Reaction and Control Thruster: Ignition Energies, Journal of Propulsion and Power, Vol 30, pp. 952-961, 2014

${ }^{22}$ Masahiro I et al (2010) Full duration firing test results of 100 kN LOX/LNG engine. Paper presented at the Space Propulsion 2010, San Sebastian, Spain, 3-6 May 2010

${ }^{23}$ Kubota I et al (2012) Current development status of LNG propulsion system. Paper presented at the 53th Conference on Aerospace Propulsion and Power, Geibunkan, Kurashiki, 4-5 Mar 2012

${ }^{24}$ Kano Y et al (2012) Overview of LNG propulsion system development. Paper presented at the 63rd International Astronautical Congress, Naples, Italy, 1-5 Oct 2012

${ }^{25}$ Taya K et al (2013) Development and test of the LOX/LNG regenerative cooled rocket engine (2nd Report). Paper presented at the 29th International Symposium on Space Technology and Science, Nagoya congress center, Nagoya, 2-9 June 2013 
${ }^{26}$ Taya K et al (2014) Development and test of the LOX/Methane regenerative cooled rocket engine. Paper presented at Space Propulsion 2014, Cologne, Germany, 19-22 May 2014

${ }^{27}$ Hiroya Asakawa et. al. “The Status of the Research and Development for LNG Rocket Engines in Japan.”, Space Propulsion May 2014.

${ }^{28}$ Applewhite, J, Hurlbert, E. “Non-Toxic Orbital Maneuvering and Reaction Control for Reusable Vehicles”, JPP Oct 1998.

${ }^{29}$ Drake, Bret, “Human Exploration of Mars Design Reference Architecture 5.0”, NASA SP-2009-566.

${ }^{30}$ Klem, M.D., Smith, T.D., Wadel, M.F., et. al. "Liquid Oxygen/Liquid Methane Propulsion and Cryogenic Advanced Development", IAC-11C4.1.5

31 “High Pressure Composite Overwrapped Pressure Vessel (COPV) Development Tests at Cryogenic Temperatures", David M. Ray, P.E., NASA Johnson Space Center, Houston, TX, USA, Nathanael J. Greene, NASA White Sands Test Facility, Las Cruces, NM, USA, Duane Revilock, NASA Glenn Research Center, Cleveland, OH, USA, Kirk Sneddon, ARDE', Inc., Norwood, NJ, USA, Estelle Anselmo, ARDE', Inc., Norwood, NJ, USA. 49th AIAA/ASME/ASCE/AHS/ASC S tructures, Structural Dynamics, and Materials Conference, Schaumberg, IL, April 7-10, 2008.

${ }^{32}$ Plachta, D.W., Sutherlin, S. G., Johnson, W.L., et. al. “Methane Lunar Surface Thermal Control Test”, NASA TM-2012-217427, 2012.

${ }^{33}$ Plachta, D.W., Johnson, W.L., Feller, J.R. “Zero boil-off system testing”, Cryogenics, Available online 23 October 2015, ISSN 0011-2275, http://dx.doi.org/10.1016/j.cryogenics.2015.10.009.

${ }^{34}$ Hastings, L.J., Bolshinskiy, L.G., Hedayat, A., et. al., “Liquid Methane Testing with a Large Spray Bar Thermodynamic Vent System”, NASA TP-2014-218197, 2014.

${ }^{35}$ Jurns, J.M., McQuillen, J.B., "Bubble Point Measurements with Liquid Methane of a Screen Capillary Liquid Acquisition Device”, NASA TM-2009-215496.

${ }^{36}$ Jurns, J.M., Hartwig, J.W. "Liquid Oxygen Liquid Acquisition Device Bubble Point Tests with High Pressure LOX at Elevated Temperatures", Cryogenics, Volume 52, Issues 4-6, April-June 2012, Pages 283-289.

${ }^{37}$ Kudlac, M. T., and Jurns, J. M. “Screen channel liquid acquisition devices for liquid oxygen.” Rep. 2006-5054, American Institute of Aeronautics and Astronautics, Reston, VA. 2006.

${ }^{38}$ Zimmerli, G.A., Vaden, K.R., Herlacher, M.D., et. al. “Radio Frequency Mass Gauging of Propellants”, NASA TM-2007-214907

${ }^{39}$ Zimmerli, G. A., Asipauskas, M., Wagner, J. D., and Follo, J. C. "Propellant quantity gauging using the radio frequency mass gauge.” Rep. 2011-1320, American Institute of Aeronautics and Astronautics, Reston, VA, 2011

${ }^{40}$ R. Jimenez, S. Flores, K. Romig, E. Hurlbert, - Characterization of a Thermodynamic Vent System (TVS) for an On Orbit Cryogenic Reaction Control Engine (RCE) Feed System, $\|$ 44thAIAA-ASME-SAE-ASEE Joint Propulsion Conference 2008.

${ }^{41}$ Flores, S., Collins, J., and Hurlbert, E., "Characterization of Propellant Distribution for a Cryogenic Attitude Control System", AIAA 2011 $5775,2011$.

${ }^{42}$ Boyle, R., Barfknecht, P., DeLee, H., et. al. "Progress on the RRM3 Cryogen Demonstration System”, Presented at the 2015 Cryogenic Engineering Conference, July 1, 2015, Tucson AZ.

${ }^{43}$ Kassemi, M., and Chato, D. (2008). "Science requirements definition, the Zero Boil-Off Tank (ZBOT) Experiment." NASA, http://issresearchproject.grc.nasa.gov/MSG/ZBOT/documents/ZBOT_SRD.pdfe (Oct. 11, 2012).

${ }^{44}$ Alan Strahan and Humberto Hernandez, Jr., "Slosh Baffle Design and Test for Spherical Liquid Oxygen and Liquid Methane Propellant Tank for a Lander", August 1, 2011, NASA Johnson Space Center, 47th AIAA/ASME/SAE/ASEE Joint Propulsion Conference \& Exhibit, Joint Propulsion Conferences, (AIAA 2011-5633)

45 J. Patrick McManamen, Eric A. Hurlbert, and Dennis J. Kroeger, ’Development and Flight Operation of a 5 lbf to 20 lbf O2/CH4 Roll Control Engine for Project Morpheus" NASA Johnson Space Center, 50th AIAA/ASME/SAE/ASEE Joint Propulsion Conference, Propulsion and Energy Forum, (AIAA 2014-3589).

${ }^{46}$ Robinson, P, Veith, E., et al., “100-lbfLO2/LCH4 Reaction Control Engine Technology Development for Future Space Vehicles,” 59th International Astronautical Congress (IAC), Sep. 2008.

${ }^{47}$ 1Villemarette, M., Hurlbert, E, Angstadt, T., Collins, J., Peters, T., Allred, J., and Mahoney, J., " 870 lbfReaction Control System Tests Using LOx/Ethanol and LOx/Methane at White Sands Test Facility," 44th AIAA Joint Propulsion Conference, Jul. 2008. AIAA-2008-5247.

${ }^{48}$ Olansen, J.B., Munday, S.R., and Devolites, J.L., "Project Morpheus: Lander Technology Development" AIAA-2014-4314, AIAA SPACE 2014 Conference and Exposition, San Diego, CA, August 2014. 
${ }^{49}$ John C. Melcher and Robert L. Morehead, Combustion Stability Characteristics of the Project Morpheus Liquid Oxygen / Liquid Methane Main Engine. NASA Johnson Space Center, Houston, TX, 50th AIAA/ASME/SAE/ASEE Joint Propulsion Conference July 28-30, 2014, Cleveland, OH AIAA 2014-3681

${ }^{50}$ Trinh, H.P., "Liquid Methane/Oxygen Injector Study for Potential Mars Ascent Engines" $36^{\text {th }}$ AIAA/ASME/SAE/ASEE Joint Propulsion Conference and Exhibit, Huntsville, AL, July 17-192000.

${ }^{51}$ Hulka, J. R., and Jones, G.W., "Performance and Stability Analyses of Rocket Thrust Chambers with Oxygen/Methane Propellants," $46^{\text {th }}$ AIAA/ASME/SAE/ASEE Joint Propulsion Conference and Exhibit, Nashville, TN, July 25-28 2010. 